\title{
Las transgresiones de Leonardo Padura: verdad y transfiguración tras el juego de Máscaras
}

The Transgressions of Leonardo Padura: Truth and Transfiguration Behind the Game in Máscaras As transgressões de Leonardo Padura: verdade e transfiguração trás o jogo de Máscaras

\section{Maite Villoria Nolla}

THE UNIVERSITY OF WEST INDIES AT MONA, JAMAICA

Profesora del Departamento de Lengua y Literaturas Modernas en The University of West Indies at Mona, Jamaica. $\mathrm{PhD}$ por The University of Nottingham, en Reino Unido. Ha escrito varios artículos para revistas especializadas en Estados Unidos, América Latina y Europa. Correo electrónico: teresa.villorianolla@uwimona.edu.jm

Artículo de reflexión

Documento accesible en línea desde la siguiente dirección:

http://revistas.javeriana.edu.co

doi:10.11144/Javeriana.cl21-41.tlpv 


\section{Resumen}

En su novela Máscaras,

Leonardo Padura se sirve de la novela negra para representar la heterogeneidad cubana y la represión político-ideológica, sexual, religiosa y artística experimentada en la isla. Su investigación, desarrollada tras el tópico de las máscaras, se enfrenta a las estructuras impuestas desde el Estado, que ha requerido que la noción de cubanidad sea representada como un paraíso socialista. Este ensayo recuerda la noción propuesta por Lezama Lima en la que el cubanismo solo puede articularse vía transfiguración poética ya que, en el transcurso de la novela, observamos cómo Padura recurre a la transfiguración como fuerza de cambio y transformación. A partir de la revelación de la realidad que hay tras las máscaras, Padura reflexiona sobre la integración simbólica del transgresor y marginal "otro" y lo sitúa en el centro de cambio del orden social.

\section{Palabras clave: Leonardo}

Padura; novela negra; revolución; transfiguración; transgresión; Cuba; detective

\section{Abstract}

In his 1997 novel Máscaras, Leonardo Padura uses the detective fiction genre to represent the repressed "other" in Cuban society, in its sexual, ideological, religious and artistic aspects. This inquiry beneath the surface and behind the masks runs counter to the structures of the Cuban State, which demands that Cubanismo be imagined / represented as a socialist paradise. This essay analyzes Padura's novel as a realization of Lezama Lima's notion that Cubanismo could only be articulated via "poetic transfiguration". But symbols are dangerous because they are poly-vocal and cannot be controlled by the authority; hence, we are confronted to the repression of the imaginary in a post-revolutionary Cuba. Through the uncovering of the masked truth about this intrafamilial murder, Padura effects a symbolic integration of Cuba's repressed otherness.

Keywords: Leonardo Padura; noir novel; revolution; transfiguration; transgression; Cuba; detective

\section{Resumo}

No seu romance Máscaras, Leonardo Padura serve-se do romance policial para representar a heterogeneidade cubana e a repressão políticoideológica, sexual, religiosa e artística experimentada na ilha. Sua pesquisa, desenvolvida trás o tópico das máscaras, enfrenta-se às estruturas impostas desde o Estado que tem precisado que a noção de cubanidade for representada como paraíso socialista. Este ensaio retrotrai a noção proposta por Lezama Lima na que o cubanismo apenas pode se articular via transfiguração poética porque no decorrer do romance, observamos como Padura recorre à transfiguração como força de mudança e transformação. A partir da revelação da realidade por trás das máscaras, Padura reflete sobre a integração simbólica do transgressor e marginal "outro" e coloca-o no centro das mudanças de ordem social.

Palavras-chave: Leonardo Padura; romance policial; revolução; transfiguração; transgressão; Cuba; detetive

\section{Cómo citar este artículo:}

Villoria Nolla, Maite. "Las transgresiones de Leonardo Padura: verdad y transfiguración tras el juego de Máscaras". Cuadernos de Literatura 21.41 (2017): 268-287. https://doi.org/10.11144/Javeriana.cl21-41.tlpv 


\section{Introducción}

Máscaras, de Leonardo Padura, pertenece a su cuatrilogía Cuarteto Habana, iniciada por Pasado Perfecto en 1991. Máscaras es la tercera de las siete novelas de Padura que dan vida al teniente Mario Conde, personaje enteramente cubano y a la vez representante del arquetipo del detective duro de la novela negra.

Padura ha mencionado repetidamente las aspiraciones con las que escribe sus novelas: tienen que ser cubanas sin perder la sensibilidad literaria. $Y$, a pesar de expresar su aversión por la escritura con intenciones políticas obvias, que considera típicas del materialismo social (Padura, "Not Your Usual Suspects: Leonardo Padura Talks to Political Affairs"), Máscaras sin duda ofrece una crítica al Estado Cubano, en particular al periodo más homófobo que se desarrolló durante la Revolución. La historia despega en un caluroso 6 de agosto del verano de 1989, día de la Transfiguración, cuando Alexis Arayán - el hijo de Faustino Arayán, el último representante cubano de Unicef- es encontrado asesinado en el Parque Habana, transfigurado de "Electra Garrigó", versión cubana de la tragedia griega de Virgilio Piñera. El caso de asesinato es asignado al teniente Mario Conde, quien se encontraba relegado a tareas de oficina tras su pelea pública con su colega, el teniente Fabricio, unos tres meses antes del suceso.

Desde nuestro primer encuentro con Conde sabemos que no estamos ante un detective ordinario. De hecho, es un escritor frustrado y es esa pasión por la escritura la que lo lleva a desarrollar ciertas teorías basadas más en la intuición que en la evidencia concreta. Además, la metaficción provee a la novela de una heterogeneidad conceptual; marco idóneo para el sujeto que encarna Conde. Desde el inicio de la novela, Conde se presenta ante el lector como un personaje que roza lo nostálgico, con ciertos rasgos de inseguridad al demostrar sus incertidumbres, principalmente sobre el camino que su vida profesional ha tomado. En realidad, Conde es una de las presencias en la novela del sujeto en transición y evolución a partir de su aprendizaje.

Sin embargo, Conde duda que sus elecciones hayan sido las más adecuadas, comparando su vida a la de sus compañeros y recordando aquellos "buenos tiempos" de un pasado que, en realidad, no fue tan bueno. Su nostalgia es palpable desde el inicio de la novela cuando somos testigos de su deseo de unirse a un partido de béisbol que algunos jóvenes juegan en la calle. Sin embargo, Conde es demasiado consciente de que "ese" ya no es su lugar, principalmente porque ahora, siendo policía, un miembro de las fuerzas represivas del país, ya no se siente cómodo entre aquellos a los que un día llamó "su gente". Conde ha cambiado; también ha cambiado su barrio, y ambas evoluciones no se han desarrollado totalmente en paralelo. Como dirá más adelante el personaje: "su 
barrio ha cambiado, transformado, travestido" (216), implicando el cambio, la transformación y el enmascaramiento de su entorno, y sin que todavía se aprecie conscientemente el suyo propio. Y, si bien en un principio Conde es "sujetador" de ciertos valores diseminados por la multiplicidad de poderes - sociales, políticos y culturales - que determinan su comportamiento, la trasformación es evidente a partir de su desacuerdo con otros personajes, principalmente evidenciados con sus diálogos con Marques. Del desacuerdo entre ambos, Padura construirá su detective, formulará su crítica social y, a la vez, revelará la heterogeneidad del ethos cubano.

La investigación conducirá a Conde a dos ambientes muy distintos. En primer lugar, al hogar de los Arayán, una familia cubana que cuenta con una situación privilegiada y, por otra parte, a la familia del famoso artista y dramaturgo caído en desgracia Alberto Marques. Marques, declarado homosexual, ha sido víctima de la homofobia del sistema, ciertamente fomentada con la revolución y, tras haber sufrido la humillación y la represión durante más de catorce años, se ha convertido en un personaje resentido, amargado y profundamente decepcionado del régimen dominante. Amigo íntimo de Alexis, Marques es una de las primeras personas en ser interrogadas por Conde en el transcurso de la investigación. Durante la interrogación, Marques explica que Alexis ni era travesti, ni le gustaba hablar abiertamente de su propia condición sexual. De hecho, lo que Marques expone es que Alexis era una persona inhibida que cargaba un gran peso de culpa por su homosexualidad. El desenlace nos conduce a Faustino Arayán, padre de Alexis, quien, consciente del hecho de la homosexualidad de su hijo y apenas antes de asistir a la conferencia de derechos humanos en Bruselas, lo mata como resultado de su propia homofobia y para silenciarlo, ya que guarda en su poder un secreto mucho más oscuro de su propio pasado.

El secreto que guarda Faustino data de 1959, cuando falsificó ciertos documentos que constataban su pronta afiliación a la revolución. Y fue con base en tal mentira que se le otorgaría una posición de privilegio y que sería nombrado embajador de Cuba en el extranjero. De ahí que las cosas no sean lo que aparentan y que estas apariencias funcionen como una cortina de humo que no permite ver la realidad. Esta es sin duda la forma como Padura critica la revolución: crítica que en la novela se presenta hilvanada por mentiras y secretos; máscaras que nuestro detective tratará de desenmascarar a lo largo de su investigación, revelando la verdad que se oculta tras ellas.

La novela representa a la sociedad habanera de finales de los años 80; un periodo crucial en el que la Unión Soviética estaba a punto de su disolución y Cuba, dependiente de la economía y el poder militar soviético, entró en un periodo de 
dureza económica y dificultades extremas conocido eufemísticamente como el Período Especial. Pero la historia de Máscaras no pretende ser la historia con mayúsculas, sino la historia de los seres humanos que conforman la sociedad. De ese modo, Padura diferencia la historia oficial de la que se construye con las múltiples voces de los individuos, enfatizando la heterogeneidad de la identidad cubana. A partir de distintas visiones individuales percibimos la escasez, las privaciones y la austeridad, así como también la corrupción, la represión y todas aquellas atrocidades cometidas por Unidades Militares durante los años 60 y 70 (UMAP), al igual que las medidas severas de 1971, en las que Marques se vio involucrado, y los horrores del éxodo de Mariel.

Por otra parte, es sabido que en Cuba los líderes lanzaron discursos homófobos como parte de la estrategia de construcción de la nación cubana. Esos discursos político-históricos se han visto usualmente influidos por la guerra y, a partir de sus prácticas, los estereotipos de género y sexo se han reforzado y canalizado. La historia cubana se ha venido construyendo sobre el principio de exclusión de ciertos grupos sociales; una historia homofóbica, patriarcal y androcéntrica cuyo objetivo ha sido proteger la ideología dominante. Por ello, tanto homosexuales como travestis se han visto como monstruos, deformados y extraños, "locas" o "pajarones" en el cubano vernacular y, por ello, han estado sujetos a la mayor de las represiones. Los homosexuales encarnaban a figuras inadecuadas, resquicios de la sociedad burguesa y, por lo tanto, no aptos para el movimiento revolucionario. Esta situación empeoró con el éxito del gobierno comunista, ya que la homosexualidad era vista como subversiva, no solo por no caracterizar la agresividad masculina necesaria e impuesta por el sistema, sino también por identificarla erróneamente como un fenómeno derivado de una clase social específica: la burguesía decadente que tenía que ser erradicada. En la novela, el dramaturgo Alberto Marques habla de esta discriminación contra los homosexuales en la isla, que se convierte en símbolo y síntoma del fenómeno. Alberto es un escritor a quien la institución cubana censuró por sus "desviaciones ideológicas". Entre sus "pecados" no encontramos únicamente la homosexualidad, sino que, peor si cabe, su actitud desafiante hacia el sistema y hacia la forma en la que los artistas y escritores fueron tratados en la década más represiva de la Revolución. En la novela, Alberto es

homosexual de vasta experiencia depredadora, apático político y desviado ideológico, ser conflictivo y provocador, extranjerizante, hermético, culterano, posible consumidor de marihuana y otras drogas, protector de maricones descarriados, hombre de dudosa filiación filosófica, lleno de prejuicios pequeño burgueses y clasistas, anotados y clasificados con la 
indudable ayuda de un manual moscovita de técnicas y procedimientos del realismo socialista. $(41)$

Este personaje encarna al escritor y dramaturgo Virgilio Piñera (19121979), y a pesar de que Piñera muriera en 1979, Padura toma licencia poética para mantenerle vivo en el personaje de Marques. De hecho, existe un estrecho paralelismo entre ambos, que incluye su "comportamiento afeminado" y su sexualidad. Además, del mismo modo que Piñera, Marques cree que es en el teatro en donde se puede presentar la realidad. Pero, además, la intertextualidad de la novela parte de la tragedia de Electra Garrigó (1948) de Virgilio Piñera, con la cual Marques comparte su autoría en la ficción.

Y será la novela negra, leída como tragedia, la que le permitirá a Padura el formato ideal para transmitir, bien sea directa o indirectamente, la crítica político-social, debido a que el duro detective privado "frequently proceed $[s]$ from the interrogation of suspects to the interrogation of society" (Christian 1 ) [el detective privado frecuentemente parte de la interrogación a los sospechosos y termina interrogando a la sociedad]. Esta interrogación normalmente nos lleva a una confesión que va más allá de la mera resolución del problema, que es indiscutiblemente el motivo central en cualquier novela negra o de detectives, sin importar su contexto cultural. Además, y también de acuerdo con Christian " $[i]$ $n$ its broadest sense, the term 'post-colonial' encompasses the members of any group - be it national, tribal, ethnic, or otherwise - which has been marginalized or oppressed and is struggling to assert itself' (2) [en un sentido más amplio, el término poscolonial considera a los miembros de cualquier grupo, sea este nacional, tribal o étnico, que haya sido marginado y oprimido y encuentre dificultades en valorarse a sí mismo].

Entre estos grupos marginales no solo encontramos a los homosexuales, sino que, en el caso que nos ocupa, la novela negra poscolonial ha sido y continúa siendo un sub-género marginado con relación al canon literario. En la novela negra poscolonial el detective es un sujeto poscolonial y no está únicamente marginado y 'otrizado' con relación a la tradición literaria, sino también con relación al detective del mundo de ficción anglosajón dominante. Por otra parte, el concepto discutido por Christian parece ser que la literatura poscolonial se ha escrito y se escribe por miembros de grupos marginados que se encuentran en una posición de lucha contra la hegemonía cultural y el neo-colonialismo (3). A partir de esta premisa, entendemos que estamos ante una triple marginalización. En primer lugar, Padura es un escritor poscolonial, un habanero marginalizado, vecino de los suburbios de la ciudad, lo que hasta cierto punto le permite una posición preferente para su 
(re)escritura de la Habana; un autor que ha creado en su escritura un detective poscolonial y nativo cubano que muestra un gran deseo de desenmascarar las contradicciones internas sociales a partir de su singular perspectiva de la sociedad. La constante lucha de Conde, dirigida claramente contra las instituciones cubanas, lo conduce a preguntarse por su pertenencia a un sistema controlado tan estrictamente, en donde todo el mundo es meticulosamente analizado e identificado: "lo sabían todo, absolutamente todo, incluso lo que ocurre íntimamente..... [cं]pero no te das cuenta de que lo saben todo? Lo jodido es eso, Conde, uno siente de pronto que está viviendo en una urna transparente o en un tubo de ensayo, no sé, y que lo ven cagar, mear y hasta sacarse los mocos..." (127). "De verdad que eso sí da miedo... A veces le dan ganas a uno de irse para la luna" (128).

Pero, sobre todo, Padura es capaz de cubanizar la tradición de la novela negra - de "gumshoe" crime fiction - y usa el género como herramienta para representar los secretos y represiones que se esconden en la nación, en la ciudad y en su tejido social. Si bien la novela, a nivel general, como espacio discursivo y estético, constituye un lugar de contestación y disidencia política, el género policiaco en particular, según el autor, tiene otras características: "One of the virtues of this genre is that one can utilize it in any way one wishes," y continúa:

The 'dark' novel can take one directly to the darkest corners of a reality, of a society, while always maintaining something that is very important to me: the possibility of communicating with readers. That is why I like the police-type novel so much - I call my novels 'false crime novels', because the crime novel structure is only a pretext to get to other places (32)

["puede utilizarse de la forma que uno desee" y continúa:

La novela negra puede llevarnos directamente a las esquinas más oscuras de la realidad, de la sociedad, mientras que al mismo tiempo mantiene algo muy importante para mí: la posibilidad de comunicarme con los lectores. Es por esto que me gusta tanto la novela de detectives - Yo llamo a mis novelas 'novelas de crimen falso' porque la estructura de novela criminal es solo un pretexto para llegar a muchos otros lugares].

Estos lugares son las áreas escondidas del Estado Cubano excluyente, cuyo mandato es imaginar y representar un paraíso socialista. De esta forma, uno puede inferir que Padura, además de su gusto personal, también ha elegido este género con normas claramente estipuladas porque, como la ciencia ficción, estas fórmulas son máscaras que permiten presentar una crítica social que escapa del radar de la censura del Estado; la censura hacia el artista que lo empujaba a 
trabajar dentro de un marco del realismo social autorizado o que, más aun, lo determinaba - y quizá siga determinando - al silencio.

\section{Máscaras. una transformación del "sub-género" literario}

La transfiguración se encuentra en la base de la novela negra ya que esta se define como la transformación o representación de una acción grave, normalmente una muerte o un asesinato, en una narrativa. Y si, por una parte, la novela negra nos permite la transfiguración del crimen, una transfiguración que podría conducir a una redención política, por otra parte ayuda a que entendamos este mundo cada vez más confuso, revelando conexiones casuales a partir del pensamiento racional. Además, más que cualquier otro género, la novela negra refuerza la idea de que la lectura es la búsqueda de significados (Cawelti, Adventure, Mystery, and Romance). En realidad, Mario Conde llevará a cabo no solo una lectura de la situación y de los eventos, sino que además mostrará su proceso de aprendizaje, lo cual le facilitará la comprensión del mundo que lo rodea y le ayudará al reconocimiento de la política de exclusión rampante que tiene lugar en su propio país. Como Tzvetan Todorov declara en su artículo "The Typology of Detective Fiction" de 1966, las historias de detectives son, por definición, narrativas sobre la lectura. En Máscaras esto es evidente ya que se invita al lector a descubrir y entender el mundo que ha sido creado en la novela, al mismo tiempo que lo hace su detective.

De hecho, es en parte a través de la lectura que Mario Conde toma conciencia, no solo del mundo de la homosexualidad - un mundo que no comprendía y que le parecía distante hasta entonces - sino también de la realidad a su alrededor. ${ }^{1}$ De esta manera, la novela convierte al lector en productor del texto (como afirma Barthes en su estudio de 1974), reafirmando a la novela negra como una poderosa herramienta para presentar su reflexión política ${ }^{2}$ y, de ahí, la predilección de Padura por este (sub)género.

\section{Apropiación cubana del género policiaco}

Recurriendo a las palabras del autor, con Mario Conde Padura ha creado " $a$ man who is a bit disenchanted, sceptical, who defends himself through irony, and

$1 \quad$ Las teorías aplicadas en el libro El rostro y la máscara, escrito por el Recio y retomadas por Conde durante una de sus entrevistas con Marques, están estrechamente relacionadas con las expresadas por Severo Sarduy en su obra La simulación (1982).

2 La participación de Hammett en el partido comunista apoya tal lectura. Las agendas políticas tanto abiertas como encubiertas que son evidentes en la narrativa del género de detectives van desde la mera paranoia política a la misoginia de Mickey Spillane o la agenda reformista liberal de Ross Macdonald. 
who has great loyalties and great phobias" ("Not Your Usual Suspects: Leonardo Padura Talks to Political Affairs") ["un hombre desencantado, escéptico, que se defiende a sí mismo con ironía y que tiene grandes lealtades y grandes fobias"]. Su desencanto le produce una alienación que lo convierte en el detective "hard-boiled" por excelencia, ya que lo empuja hacia la búsqueda de la verdad y a tratar de erradicar lo más vil de la condición humana (Grella 104). Pero la alienación de Conde no está condicionada únicamente a la diferencia de clase, a modo de Sam Spade o Marlowe, sino que es específica al contexto cubano. Conde ha vivido en el mismo barrio de la Habana durante toda su vida y está profundamente imbuido de las normas culturales cubanas. Como se ha mencionado anteriormente, Conde es "sujetador" de ciertos principios y valores, y está "sujetado" por la multiplicidad de poderes que determinan su comportamiento. Sin embargo, sigue sintiéndose alienado y distanciado de muchos aspectos de la Cuba contemporánea, especialmente de la política autoritaria y del pensamiento grupal, así como de la censura interna que todo ello produce. Durante la novela observamos que distintos devenires lanzan a los sujetos al margen del patrón de comportamiento convencional, y se reconoce la diferencia, el desplazamiento y la autoconstitución del sujeto, rompiendo con la tendencia homogeneizante global. No es ninguna sorpresa entonces que Padura diga que, para la ortodoxia cubana, Conde era un tipo "políticamente incorrecto" (Padura, "Not Your Usual Suspects: Leonardo Padura Talks to Political Affairs"). La crítica dirigida hacia el pensamiento grupal y contra la censura del Estado Cubano y sus seguidores es, sin duda, una de las razones de su incorrección política.

Pero, sobre todo, Padura sigue el dictado que Chandler formula en "The Simple Art of Murder". Chandler dictamina que en todo aquello que pueda llamarse arte hay siempre una posibilidad de redención (Chandler); necesidad de redención que es obvia en la sociedad cubana, si logramos descontextualizar el concepto y extraerle su significado específicamente religioso, que parece también enmarcado en la novela. Pero no hay redención sin reconocimiento ni comprensión del mundo tras la máscara. En definitiva, esta nos encuentra negándonos a reconocer la realidad.

Si el arte literario pudiera traspasar los límites del género - de hecho, se ha mencionado anteriormente que la fórmula no importa tanto como las posibilidades de subversión y de disfrazar ciertos contenidos que ofreceuno podría ver que, mientras Chandler y Hammett emplearon un lenguaje claramente vernacular callejero en la actualización de una ética humanista secular, Padura emplea el cubano vernacular: lenguaje en el que celebración y crítica se encuentran interrelacionados. El género criminal y la novela negra, 
conjuntamente con su homólogo cinematográfico, desarrollaron un código de conducta masculina: un comportamiento sagaz unido a un lenguaje vernacular ingenioso y ocurrente que se vio profundamente influenciado por los sarcásticos héroes que luego de la I Guerra Mundial figuraron en la escritura de Ernest Hemingway. Esta obvia masculinización del lenguaje ayuda a (re)edificar una identidad masculina de hombre duro caracterizada por la creación de una coraza exterior que suprime cualquier muestra de afecto. ${ }^{3}$ Sin embargo, la mayoría de los detectives literarios tiene una apariencia dura - una máscara o, como Christopher Brue (en su publicación de 2005) declara, una "fantasía cultural" que se extiende al día a día - pero un interior mucho más romántico e idealista. Esta disyuntiva que surge entre la máscara exterior y su más interna imaginación femenina está muy presente en Conde, quien experimenta una fuerte tensión entre su pensamiento y su actitud externa: rasgo que transgrede el fundamento básico de la novela negra. Además, la ambigüedad juega un papel definitorio en el mensaje de la novela, ya que mediante la tensión experimentada por Conde y la aparición de personajes de sexualidad cambiante no solo se desestabiliza el prototipo del detective y el modelo heterosexual de la nación, sino que, a la vez, la novela se establece como un arma de subversión política y deconstruye las definiciones totalizadoras (pre)establecidas.

La tensión interna del detective sale a flote principalmente en los encuentros que tiene con Marques, ya que ambos juegan a mantener posiciones extremas. En sus conversaciones, su falta de consenso evidencia su disentimiento entre realidades y sus diálogos actúan a modo de "diferendo", 4 permitiendo construir una realidad "otra" (como señala Lyotard en su estudio de 1983). Y siendo Conde el portador de valores instituidos que determinan su comportamiento, es a partir de estos diálogos que su auto-percepción evoluciona, encarnando al sujeto móvil y transitivo.

Regresando a la novela negra y a la figura de Conde como detective, vemos que las narrativas cortadas en primera persona de Hammett y Chandler son a menudo cínicas sobre el sórdido mundo social que ellos observan y que solo en raras ocasiones hablan de sí mismos o de sus sentimientos, mientras que Conde a menudo entabla monólogos interiores profundos sin olvidar la metaficción crea-

3 En Murdering Masculinities: Fantasies of Gender and Violence in the American Crime Novel, Greg Forter ha desarrollado un argumento interesante sobre la constitución y disolución de la coraza exterior del detective duro.

4 Entendemos aquí por "diferendo" la auto-percepción de uno en constante diálogo con el otro y la construcción de una realidad "otra" a partir del desencuentro de distintas realidades. 
da por sus propios cuentos, sueños e historias ficticias. Además, Conde rompe con ese ojo solitario del detective privado. Como Dennis Porter escribe en su artículo "The private eye", el investigador en la novela negra es "un solitario, un ojo de un hombre que no pertenece a organización alguna, como un scout o un cowboy; un ojo que no confía en nadie, un ojo que tiene licencia para observarlo todo; e incluso, por extrapolación, un ojo de alquiler" (1). En la revisión del género desarrollada por Padura, Conde es un hombre que, si pertenece hasta la médula a una organización y si en ocasiones es un policía desafectado, a la vez es un animal social que depende de sus amigos y de la rutina de su comunidad, aunque en ocasiones se encierre también en su soledad.

Así pues, en contraste con la superficialidad del detective clásico, con sus frías observaciones de un mundo sin esperanza, el estilo de Padura está cargado de esa ansiedad y de esa tensión que sufren las personas que viven bajo una presión constante, y despliega el desfiguramiento que esa presión produce. Del mismo modo, su estilo admira el rebusque de la gente que saca el mejor partido de lo inexistente y encuentra felicidad en un mundo de escasez y opresión. Conde vive en la Habana contemporánea; una olla a presión que parece reforzar esa personalidad dual, ese exterior o esa máscara tras la que el personaje esconde un alma romántica y artística, afuera de los parámetros del realismo social.

Y, al mismo tiempo, el texto comparte los desafíos y luchas de una identidad sexual que es analizada por Susan Hayward en Cinema Studies: Key Concepts (2000). En Máscaras encontramos conflictos de género e identidad, y los marcos, límites y categorías sexuales aparecen claramente cuestionadas por Conde. La actitud del detective, a pesar de haber sido construida y delineada por la ideología del poder, cuestionará las divisiones de género institucionalizadas. Incluso la masculinidad del detective se ve amenazada, ya que, durante su proceso de lectura y aprendizaje, es capaz de darse cuenta de que la identidad sexual es una construcción, descubriendo la crisis de la tan aclamada masculinidad cubana. Es por ello que, en la novela, Conde expresa su progresiva alienación de los parámetros culturales permisibles de identidad masculina, deseo y éxito creados por el discurso cubano.

Aun así, nos encontraremos con muchas contradicciones en la novela. Mientras Conde parece compartir los principios éticos construidos por el sistema, al mismo tiempo se preocupa por el significado de la vida y la muerte desde una posición existencialista. Su personaje se encuentra en constante cambio y evolución. En un principio, la perspectiva de Conde en cuanto se refiere a la homosexualidad, está fuertemente basada en los estereotipos construidos por el Estado. Es por ello que considera a los travestis y al travestismo como una 
desviación de la norma y como un defecto de la naturaleza; de ahí que describa al homosexual a partir de jocosas caricaturas, de forma reiteradamente condescendiente y con rasgos principalmente definidos por su negación: "aquella mujer que no lo era", "una mujer sin los beneficios de la naturaleza, falsa mujer" y "a versión limitada de la mujer con la entrada más apetitosa clausurada por la caprichosa lotería de la naturaleza" (35). Sin embargo, tras sus lecturas y los varios encuentros con Marques, la propia sexualidad de Conde, tanto en relación con hombres como con mujeres, es más ambigua y, de hecho, desarrolla un creciente interés por el tema. Esta atracción hacia el mundo subterráneo y desconocido por él hasta entonces, lo conduce a acompañar a Marques a una fiesta gay. Marques le advierte que debe analizar lo que va a encontrar en la fiesta como el fruto de la represión impuesta por el sistema: "Lo que usted quiere saber no es demasiado agradable, se lo advierto. Es sórdido, alarmante, descarnado y casi siempre, trágico porque es el resultado de la soledad, de la represión eterna, de la burla, la agresión, el desprecio y hasta del monocultivo y el subdesarrollo" (138).

Sin embargo, la naturaleza ambigua de los invitados a la fiesta sirve además como ejemplo del desvanecimiento y/o deconstrucción de los límites de género, que atenúa cualquier distinción entre masculinidad y feminidad. Del mismo modo, la fiesta gestiona una visión queer que cuestiona la propia estabilidad de la definición de una identidad política, artística o sexual. En realidad, este evento rompe claramente con el binarismo de género existente dentro del marco patriarcal caribeño, en particular cubano, y refuerza el espacio intermedio que ocupan aquellos individuos empujados socialmente al margen, no tanto por un cambio de identidad sino por el desplazamiento que ejemplifican. Es a partir de los personajes que asisten a la fiesta que podemos apreciar la verdadera naturaleza heterogénea de la identidad nacional: "Alguien con mentalidad moscovita pensó que la uniformidad era posible en este país tan caliente y heterodoxo donde nunca ha habido nada puro" (214). Pero esa noche, incluso Conde se sorprende a sí mismo cuando da lumbre a un cigarrillo "a lo Humphrey Bogart" para "aumentar su cotización en aquel mercado rosa" (140). Conde se siente observado y deseado por los "maricas" y disfruta de alimentar esa atracción. Esta ambigüedad sexual recuerda de nuevo la identidad transitiva del sujeto y la evolución y desenmascarización de Conde. Finalmente, se encuentra con "nalguitas de gorrión", sujeto ambisexual que transgrede el patrón heterosexual americano de Conde; una mujer muy "masculina" con la que Conde acaba teniendo sexo anal. Esta mujer con cuerpo semi transformado indica que la identidad no corresponde a su constitución somática y enfatiza el carácter ilusorio de las apariencias. Pero, además, con "nalguitas de gorrión" aparece una lucha erótica que crea nuevas 
categorías. De esta manera, la novela de Padura nos presenta, a través de esta fiesta, una perspectiva ventajosa desde la cual leer, y críticamente re-examinar, tanto las pre-concepciones sociales como las políticas de género fomentadas en Cuba. Tal como declara Conde, las teorías expuestas por Marques le permiten pensar y ver a los sujetos a través de un prisma muy distinto: "ya sabes que no resisto a los maricones pero este tipo es muy distinto... el muy cabrón me ha puesto a pensar" (59).

A partir de sus conversaciones con Marques, Conde es capaz de reflexionar y entender otra realidad, ya que el personaje le instruye sobre la historia gestionada y reprimida por el discurso de la nación. Este re-contar de Marques indica cómo la memoria puede ser liberadora si se re-imagina; si corregimos el hábito de reprimir el re-conocimiento. Al re-imaginar el pasado tomamos los pasos necesarios hacia la transformación de una identidad presente y abrimos paso para la reconstrucción de las políticas de inclusión con una visión mucho más integradora de una sociedad futura. A pesar de ello, la re-imaginación cultural no es posible sin un recuerdo cultural y, sin duda, la literatura facilita este re-imaginar, ayudando para que evitemos repetir las políticas exclusivistas del pasado, colaborando con proyectos más democráticos y dando paso a una gama de nuevas posibilidades.

Así pues, parece ser que las convenciones de la novela negra ofrecen una forma de reconciliar las dos caras de la personalidad de Conde, implicando que también la sociedad puede ser reconciliada y evolucionar. Además, el que la historia investigue la muerte de un homosexual, transvestido y transfigurado en el momento de su muerte, permite reflexionar sobre la realidad existente bajo las máscaras, y descubrir cómo la heterogeneidad de los sujetos y las sexualidades camaleónicas reflejan la crisis y el derrumbe de la homogeneidad maniqueísta de los discursos tradicionales.

\section{Tragedia Cubana}

No sé si notó que todo esto es una Tragedia Griega, en el mejor estilo de Sófocles, llena de equívocos, historias paralelas ... y personajes que no son quienes dicen que son, o que ocultan lo que son, o han cambiado tanto que nadie sabe quiénes son, y en un instante inesperado se reconocen trágicamente. (220)

John Cawelti declara que "las historias de detectives han presentado tradicionalmente temas religiosos y morales" (Adventure, Mystery, and Romance 54). En la novela negra americana del siglo XX, continúa diciendo, "los temas se desarrollan frecuentemente en historia de detectives cuyo ethos personal entra en conflicto con 
una sociedad inmoral y corrupta" (59). En la novela de Padura, uno esperaría que el detective, como el héroe americano, hubiera conseguido trasformar todo lo malo en algo positivo, ya que necesita convertirse en héroe para reparar el frágil tejido social perturbado por el criminal (Cawelti, "Chinatown and Generic Transformation in Recent American Films"). Otra premisa sería comparar la novela negra con la tragedia: de ahí que sus audiencias esperen ciertas respuestas emocionales comunes; una forma de catarsis similar a la redención.

Es precisamente esta catarsis la que permite que Máscaras pueda leerse a modo de tragedia, aproximándose a la definición clásica del género. A pesar de que el conjunto de la novela negra no se centre en la caída de una gran persona, causada por una confrontación consciente con las imperfecciones o fallas de carácter, la novela de detectives a menudo sí se desarrolla como una tragedia, si tenemos en cuenta que provee un tipo de catarsis para el lector. ${ }^{5}$ En este sentido, la identidad del personaje vive un momento de anagnórisis, reconocimiento de su destino que, a pesar de no purificarlo, le ayuda a ver la vida con mayor claridad y a entenderla como un todo, tal y como Lauchlan Watt escribió en su estudio Attic and Elizabethan Tragedy (1908). Podríamos llegar a decir que, como la tragedia griega, el detective "show [s] the hidden cords which moved events" (muestra los hilos que mueven los acontecimientos) y en ocasiones sirve como una escuela de conducta que ayuda a crear una moralidad pública (Watt 16). Tanto la tragedia como la novela negra son encarnaciones modernas de arquetipos de los mitos clásicos como el de Edipo. Y, al igual que muchos mitos, fábulas y laberintos, la historia del detective duro da pie a distintas interpretaciones que nos ayudan a descubrir el arquetipo y, consecuentemente, conlleva una transmutación del significado social.

En el ensayo de W.H. Auden "The Guilty Vicarage", se establece un paralelismo entre la teoría aristotélica de la tragedia y los elementos aceptados por el canon de la novela negra. Entre los elementos comunes más importantes encontramos, por una parte, el encubrimiento y la confusión —el inocente parece culpable y el culpable, inocente-, y la manifestación, el reconocimiento y presentación del verdadero culpable, por otra. El diagrama más formal de Auden para el género se presenta como sigue: un estado relativamente pacífico antes de cometerse el asesinato, un número de pistas falsas que se prestan a la confusión, la solución del rompecabezas que culmina con el arresto del asesino y la tran-

5 Sin embargo, la idea de que la tragedia solo puede describir a aquellos con poder y altos privilegios ha cambiado a lo largo del tiempo. De hecho, hay una creencia moderna de que la tragedia también puede representar y aludir a la gente común en su entorno diario. 
quilidad tras la resolución del caso (14). Padura parece recurrir al mismo patrón cuando nos sitúa en el hogar de Alexis, el joven asesinado en el parque, en donde parecía estar todo limpio y perfecto justo antes de que ocurriera la tragedia. Pero Padura va más lejos, ya que parece referirse al estado general de su propio país, enfatizando la diferencia existente entre las apariencias y la situación real.

Howard Barker declaraba que "in the contemporary theatre you emerge from tragedy equipped against lies" (13) [en el teatro contemporáneo se sale equipado contra las mentiras]. Y esta es ciertamente parte de la función que realiza la tragedia en la que se encuentra el detective. Las mentiras son las que finalmente permitirán encontrar la verdad, y Padura desarrolla y aplica aquello al contexto cubano. Ross Macdonald, a partir de los años 6o, adaptó conscientemente dicha teoría aristotélica a la novela negra. El detective de Macdonald, Lew Archer, es concebido como un coro peripatético, extravagante y hasta cierto punto absurdo; y el lugar del destino o del deseo de los dioses, Macdonald lo sustituye, por la psicología familiar, con la fuerza inexorable de la historia que es propulsada hacia un final irremediablemente trágico (Sharp 407).

Actualizando y traduciendo el proceso de transformación genérica, Padura parece haber sustituido el decreto de los dioses de la tragedia clásica, no solo con la psique de una familia disfuncional, incluyendo a Arayán como al padre homofóbico, sino, además, con un sistema político que reemplaza a la familia y que modela el destino de los individuos a partir de políticas y prácticas. No cabe duda de que, en Máscaras, Padura revela la división y desintegración de una familia cubana; una familia que vive de las apariencias y que aplica la ideología del Estado, provocando el distanciamiento entre sus miembros. De este modo, Padura representa al Estado Cubano como la fuerza inexorable de la historia que impulsa a los personajes hacia distintos finales trágicos. Por ello, el texto implica que es únicamente al enfrentarse a una tragedia que el hombre se autolibera y obtiene purificación y redención. El sacrificio de Alexis, ejecutado al nivel de sus "pecados sexuales", lo libera y, con su muerte, se alcanza el punto más álgido de la tragedia. Con su muerte, Alexis obtiene su redención.

No obstante, el asesinato y la muerte del hijo de Faustino Arayán van mucho más lejos de cualquier interés individual. Con su planeada muerte, fuera de la farsa y la representación, Alexis trata de cambiar la sociedad; de ahí que su transformación alcance real trascendencia. Por ello, a pesar de ser la víctima, Alexis se convierte también en el héroe de la novela, y es él quien, incapaz de conseguir la autoridad sobre su propia vida, es glorificado con y tras su muerte. El impacto de la novela reside en su paradoja: en Máscaras no es el hombre masculino socialista, el "hombre nuevo", quien trae consigo el cambio socio-político para Cuba, sino 
el transvestido, el transgresor de la norma, el "otro" reprimido. El hombre que ya aparecía en el neo-barroco de Sarduy con su condición ambigua y cambiante. Como nos explica Conde: "Ese cabrón estaba loco y se transfiguró para entrar en su propio calvario" (76). Un calvario con gran significado: la liberación de una minoría reprimida.

\section{La transfiguración y el retorno del "otro" marginado}

Al revelar la sucia realidad tras la fachada, Padura también nos muestra una Habana distinta; la otra ciudad marginal, en donde el crimen, el desorden y el exceso se hallan continuamente al acecho, merodeando tras la controlada disciplina revolucionaria. La mayor frustración de Conde deriva de su desconocimiento de los cambios de la ciudad; de su deterioro progresivo, debido, según algunos personajes de su entorno, a la entrada del 'progreso'. La ciudad de Padura queda lejos de aquella Habana monumental descrita por Carpentier, colaborando, de alguna manera, con el proceso de desmitificación del imaginario de la ciudad y con su fragmentación. Ciertamente, Padura se enfrenta a temas como la hegemonía y la fragmentación al no presentar a la ciudad como un todo homogéneo, sino como un espacio leíble, heterogéneo, con una distribución imprecisa de las funciones urbanas y basada en un discurso de identidad nacional que ignora lo marginal y que rechaza los intersticios. Quizá estemos presenciando el epitafio del "hombre nuevo" que mira con impotencia la transformación de la ciudad, plagada por el crimen y las transgresiones sexuales. Y para todo ello, Conde necesita reconectarse con el fin de ser capaz de descubrir los signos ocultos de la Cuba contemporánea que no pueden ser interpretados bajo un código homogéneo, bajo las normas impuestas desde el Estado o bajo las narrativas integradas al canon literario tradicional. En esta perspectiva, la transformación de Alexis es una versión de lo que Lezama Lima llamó la "transfiguración poética" de los elementos de la sociedad cubana que han sido marginados por las normas impuestas desde el Estado. ${ }^{6}$ De este modo, la transfiguración no solo se obtiene a partir de la transformación del género literario sino que, en Máscaras, esta se encuentra además en el centro de la narrativa, y será a partir de dicha

6 La poética de la transfiguración era para Lezama Lima la única forma de definir lo que significaba ser cubano y de cambiar la realidad del hombre caribeño obligado a ver la vida como un paraíso. De hecho, Lezama Lima espera una transfiguración; una reinvención de América y el Caribe, y así lo expresa en su trabajo: "Estamos en la oscuridad, de la cual en cualquier momento podemos recibir el Espíritu Santo y transfigurarnos" (Poesía completa 105). 
transformación que el "otro" alcanzará su redención. En realidad, la muerte de Alexis Arayán exige el retorno de lo que ha sido reprimido o rechazado por y para la historia de la nación. Y es a través de su transformación, en el mismo día de la Transfiguración de Cristo, que reaparece y se glorifica lo que había sido reprimido. Es sabido que el prohibir a la gente discutir sus ideas y sentimientos de una forma abierta y distendida no significa que lo silenciado o los silenciados desaparezca(n). Al contrario, continuamente presionan para reaparecer en la conciencia y entrar en acción. Pero, además, el forzado silencio prueba ser perjudicial para el bienestar de los individuos y, consecuentemente, para la sociedad en su totalidad.

De esta manera, podríamos decir que los problemas más severos en nuestra cultura se han visto exacerbados por la imposibilidad de discutir las ideas que eran inaceptables para el pensamiento político dominante. Es así como la transformación de Alexis implica la conversión del individuo, y el desenmascaramiento de los sentidos más íntimos entra en conflicto con el pensamiento colectivo: "ese travesti no se vistió para exhibirse ni para salir a cazar, Manolo. Estaba buscando algo más difícil de encontrar. La paz, tal vez. O la venganza, qué se yo" (90).

¿Qué buscaba Alexis? Provocar, sorprender, abandonar su "Yo", incumpliendo las normas establecidas y el orden simbólico. Por ello, y como ya se ha mencionado, su transfiguración no es únicamente externa sino interna y, además, se convierte en una llamada de cambio social. De acuerdo con Stephens: "Transfiguration could lead to political redemption often as a blood sacrifice which atones for the sins of exclusion and sets a moral tone necessary for the enactment of inclusive democracy" (95) [: La Transfiguración puede conducirnos a una redención política a menudo en forma de sacrificio de sangre que expía las culpas que siente el excluido y establece un tono moral necesario para la promulgación de la democracia inclusiva]. Sin embargo, mientras esto explicaría cómo el "otro" reacciona a su marginalización a partir del enmascaramiento, como explica el Marqués, "una máscara blanca es ahora su propio rostro" (225); la máscara es vista también como parte de uno mismo, retratando la esencia de la cubanidad, de lo cual Piñera era exponente y profeta. Por ello, la transfiguración de Alexis muestra complejidades políticas e ideológicas, tanto emocionales como estéticas, y su muerte se convierte en una metáfora del regreso de lo reprimido para redimir a la nación. De hecho, la transfiguración de Alexis va dirigida al modelo marxista-socialista, que reprime la expresión e identidad barrocas genuinamente cubanas, consideradas peligrosas por sus elementos simbólicos y por sus múltiples lecturas. 


\section{Conclusión}

La historia tradicional de detectives o la novela negra muestra a la sociedad civil como un régimen corrupto en el que reina la duda, la confusión y el crimen. Esto es cierto en Máscaras, en donde Conde no entiende su propio mundo y debe continuamente buscar una realidad que, en última instancia, no puede encontrarse. Pero su confusión no hace más que revelarnos su propia interrogación a la sociedad cubana, y clama por una transfiguración socio-política que reemplace al silencio y la represión por una existencia en libertad.

Aun más, podríamos afirmar que Máscaras encarna un mea culpa al denunciar los abusos homofóbicos perpetrados por la Revolución Cubana. Aunque algunos críticos hayan discutido que la novela no indaga en el carácter esencial natural de los géneros (Bejel 112) y que, por ello, es difícil llegar a posiciones políticas emancipadoras, en lo que se refiere a la diferencia socialmente construida de la sexualidad humana, Máscaras sí deconstruye las categorías fijas de identidad y combina motivos de ambigüedad sexual — de hecho, revisa las obras de Sarduy en donde la heterogeneidad era el elemento esencial de la cubanidad y el ser caribeño-. Sin embargo, sí es aplicable la afirmación de Bejel respecto a la vacilación y tensión de Conde que podría acomodarse a un colectivo más amplio: "if there is still vacillation between whether the genders are stable categories endowed by 'wise nature' or whether they are social constructs produced by repressive discourse, it is difficult to deconstruct homophobic prejudices and their sustaining structures"(177) [si todavía existen dudas entre si los géneros son categorías estables otorgadas por la naturaleza o bien son construcciones sociales producidas por un discurso represivo, resulta difícil deconstruir prejuicios homofóbicos y las estructuras que los sostienen].

Lo cierto es que, en Máscaras, Padura trata de crear un diálogo con el discurso oficial homofóbico y abrir una nueva línea de pensamiento. Es solo desenmascarando la represión y '(auto)reconociendo' que se puede crear una forma de vida posible y coherente. De esta manera, Padura reclama el cambio a partir de la heterogeneidad y de la transgresión a las normas (pre)establecidas por un Estado patriarcal y homogeneizante.

\section{Obras citadas}

Auden, Wystan Hugh. "The Guilty Vicarage". Detective Fiction, a Collection of Critical Essays. Ed. Robin Winks. Englewood Cliffs: Prentice Hall, 1980. 11-18. Impreso. Barker, Howard. Arguments for a Theatre. London: John Calder, 1989. Impreso. Barthes, Roland. S/Z. New York: Hill and Wang, 1974. Impreso. 
Barthes, Roland. "The Death of the Author". Modern Literary Theory: A Reader. Eds. Philip Rice y Patricia Waugh. London: Edward Arnold, 1993. Impreso.

Bejel, Emilio. Gay Cuban Nation. Chicago - London: The University of Chicago Press, 2001. Impreso.

Brue, Christopher. Hard-boiled masculinities. Minneapolis:

University of Minnesota Press, 2005. Impreso.

Cawelti, John G. Adventure, Mystery, and Romance. Chicago, Illinois: The University of Chicago Press, 1976. Impreso.

Cawelti, John G. "Chinatown and Generic Transformation in Recent American Films". Film Theory and Criticism: Introductory Readings. Eds. Gerald Mast, Marshall Cohen y Leo Braudy. New York: Oxford University Press, 1992. 498-511. Impreso.

Chandler, Raymond. "The Simple Art of Murder". The Art of the Mystery

Story. Ed. Howard Haycraft. New York: Carrol, 1985. 222-37. Impreso.

Christian, Ed, ed. "Introducing the Post-Colonial Detective: Putting Marginality to Work". The Post-Colonial Detective. London: Palgrove, 2001. 1-10. Impreso.

Fenimore Cooper, James. The Last of the Mohicans. London

- New York: Pinguin Classics, 1986. Impreso.

Forter, Greg. Murdering masculinities: Fantasies of Gender and Violence in the American Novel. New York: New York University Press, 2000. Impreso.

Grella, George. "Murder and the Mean Streets. The Hard-Boiled

Detective Novel". Contempora (March 1970): 6-15. Impreso.

Grella, George. "The Hard-Boiled Detective Novel". Detective

Fiction: A Collection of Critical essays. Ed. Robin Winks.

Englewood Cliffs: Prentice-Hall, 1980. 103-120. Impreso.

Hayward, Susan. Cinema Studies: Key Concepts. London

- New York: Routledge, 200o. Impreso.

Hutson, Lorna. "Rethinking the 'Spectacle of the Scaffold': Juridical Epistemologies and English Revenge Tragedy". Representations 89.1 (Winter 2005): 30-58. Impreso.

MacDonald, Ross. "The Writer as Detective Hero". Detective

Fiction: A Collection of Critical Essays. Ed. Robin Winks.

Englewood Cliffs: Prentice-Hall, 1980. 223-234. Impreso.

Lima Lezama, José. La cantidad hechizada. La Habana: UNEAC, 1970. Impreso.

Lima Lezama, José. Poesía completa. La Habana: Instituto del Libro, 1970. Impreso.

Lima Lezama, José. Paradiso. Madrid: Cátedra, 2003. Impreso.

Lyotard, Jean-Françoise. The Differend: Phrases in Dispute. Trad. Georges Van

Den Abbeele. Minneapolis: University of Minnesota Press, 1988. Impreso.

Padura, Leonardo. Máscaras. Barcelona: Tusquets, 2005. Impreso. 
Padura, Leonardo. "Not Your Usual Suspects: Leonardo Padura Talks to Political Affairs". Political Affairs (April 2006). Web.

Porter, Dennis. "The private eye". The Cambridge Companion to Crime Fiction. Ed. Martin Priestman. Cambridge: Cambridge University Press, 2003. 95-113. Impreso.

Sarduy, Severo. La simulación. Caracas: Monte Ávila, 1982. Impreso.

Sharp, Michael. "Plotting Chandler's Demise: Ross Macdonald and the NeoAristotelian Detective Novel". Studies in the Novel 35 (2003): 405-26. Impreso.

Stephens, Gregory. "What's become of our Bliss': Transracialism and Transfiguration in Ralph Ellison's Juneteenth." Free Enquiry in Creative Sociology 30.1 (June 2002): 95. Impreso.

Todorov, Tzvetan. "The Typology of Detective Fiction". The Poetics of Prose. Ithaca: Cornell UP, 1966. 42-52. Impreso.

Watt, Lauchlan Maclean. "The Chorus". Attic and Elizabethan

Tragedy. London: J.M. Dent \& Sons, 1908. 13-17. Impreso. 